\title{
PRODUÇÃO DE VERMICOMPOSTO A PARTIR DA CRIAÇÃO DE MINHOCAS Eisenia foetida COMO ALTERNATIVA DE PRODUÇÃO PARA AGRICULTURA FAMILIAR
}

\author{
Regiane da Silva Miranda ${ }^{1}$; Andrea Hentz de Mello²; Rosana Quaresma Maneschy ${ }^{3}$; \\ Fernando Michelotti ${ }^{4}$. Pará (UFPA), bolsista PIBEX-2011, remirandaagro@ hotmail.com
${ }^{2}$ Professora Adjunta II da Faculdade de Ciências Agrárias de Marabá (FCAM) da Universidade Federal do Pará (UFPA), andreahentz@ufpa.br
${ }^{3}$ Professora Adjunta II da Faculdade de Ciências Agrárias de Marabá (FCAM) da Universidade Federal do Pará (UFPA), romaneschy@ufpa.br
${ }^{4}$ Professor Assistente IV da Faculdade de Ciências Agrárias de Marabá (FCAM) da Universidade Federal do Pará \\ ${ }^{1}$ Discente do curso de Agronomia da Faculdade de Ciências Agrárias de Marabá (FCAM) da Universidade Federal do \\ (UFPA), fmichelotti@ufpa.br
}

\begin{abstract}
RESUMO: A utilização de vermicomposto é uma das alternativas que podem auxiliar na minimização por insumos químicos na produção vegetal e estimular a transição agroecológica na agricultura familiar. Este trabalho tem como objetivos desde 2007, desenvolver e difundir tecnologias de baixo custo para a reciclagem de resíduos vegetais através da criação de minhocas (Eisenia foetida) que possam ser utilizados nos sistemas agroflorestais (SAF) dos agricultores familiares de Marabá e região. As atividades desenvolvidas no curso de Agronomia da Universidade Federal do Pará (UFPA) - Campus Universitário de Marabá e nos projetos de pesquisa e desenvolvimento fomentaram as ações de pesquisa e extensão deste trabalho, sendo elas: a implantação e acompanhamento de minhocário experimental no campus da UFPA, outro na Federação das Cooperativas da Agricultura Familiar do Sul do Pará (FECAT), e em Assentamentos da região, bem como distribuição de matrizes para a formação de minhocários nos assentamentos e distribuição do vermicomposto. Como resultados desse projeto que articulou as atividades ensinopesquisa-extensão envolvendo docentes, discentes e técnicos junto a agricultores familiares, podemse destacar: dias de campo e palestras para a difusão da tecnologia, distribuição de matrizes de minhocas e a implantação de cinco minhocários com alta produção de minhocas e vermicomposto.
\end{abstract}

PALAVRAS-CHAVE: agricultura familiar, minhocário, insumos biológicos.

\section{VERMICOMPOST PRODUCTION FROM THE CREATION OF WORMS Eisenia foetida ALTERNATIVE PRODUCTION FOR FAMILY FARM}

\begin{abstract}
The use of vermicompost is one of the alternatives that can assist in the minimization of chemical inputs in crop production and stimulate the agroecological transition in family farming. This study aims since 2007, developing and disseminating low-cost technologies for waste recycling plant by raising earthworms (Eisenia foetida) which can be used in agroforestry systems (AFS) of the farmers in Marabá and region. The activities developed in the course of Agronomy, Federal University of Pará (UFPA) - University Campus in Marabá and in the research projects and development fostered further research and extension of this work, they being: the implementation and monitoring of earthworm experiment on the campus of UFPA, another at the Federation of Family Farming Cooperatives of southern Pará (FECAT), and in the Settlements of the region, as well as distribution headquarters for the formation of earthworm in the settlements and distribution of vermicompost. The results of this project that articulated the activities of teaching and research-
\end{abstract}


extension involving teachers, students and technicians with family farmers, can be highlighted: field days and lectures for the diffusion of technology, distribution of arrays of worms and deployment of five earthworm with high production of earthworms and vermicompost.

KEYWORDS: earthworm, family farming, organic inputs.

\section{INTRODUÇÃO}

A viabilidade da criação de minhocas em larga escala já era observada em 1940, principalmente nos Estados Unidos, sendo que neste país as minhocas já eram cultivadas em canteiros sofisticados, tal fator consagrou o país como Pátria da minhocultura. No Brasil a minhocultura é uma atividade recente e pouco conhecida, mesmo assim devido aos baixos custos exigidos em sua implantação, muitas pessoas têm se interessado pela atividade seja como fonte de proteína para a alimentação de pequenos animais ou para a produção de húmus (MARTINEZ, 2006). Os agricultores sempre foram ótimos observadores da natureza e desde muito tempo aprenderam a diferenciar à sua maneira, os solos pobres dos solos férteis. Um dos principais elementos que ajudava nessa diferenciação era a presença de minhocas: sua existência nas áreas de cultivo era geralmente associada às melhores produções. Infelizmente, as modernas técnicas intensivas de preparo e manejo de solo promoveram a degradação dos solos reduzindo seus teores de matéria orgânica e, conseqüentemente, a população de minhocas nos campos (SHIEDECK, 2006).
Atualmente com a exploração agrícola cada vez mais intensa, assim como a utilização de insumos (fertilizantes, adubos, defensivos e herbicidas) e falta de um planejamento e acompanhamento juntos aos produtores para uma melhor gestão dos recursos naturais, é cada vez mais necessário o desenvolvimento de tecnologias de baixo custo que visem sanar ou pelo menos minimizar os danos ambientais e garantir fonte de renda, não apenas para o pequeno produtor, mas também para aqueles que pretendem produzir em uma escala maior (SANTOS, 2009). Martinez (1995) discute a problemática do descarte de resíduos orgânicos, que é crescente e que vem sendo enfrentada por muitos países, mas que poderia ser amenizada através de adoção de práticas simples. Entre essas práticas, encontra-se a minhocultura e a vermicompostagem, as quais utilizam o excepcional potencial das minhocas em transformar e reciclar resíduos orgânicos, contribuído com a qualidade dos solos agrícolas e do meio ambiente.

A criação de minhocas é uma alternativa viável em amplos os aspectos (econômico, ambiental e agronômico), devido o aproveitamento de materiais oriundos da própria propriedade, por melhorar os solos e 
exigir pouca mão-de-obra. A criação de minhocas não se restringe apenas à zona rural, justamente pela facilidade de construção do minhocário e pelo manejo desses pequenos animais ser relativamente simples. Dependendo da espécie e do objetivo a serem criadas elas podem ser mantidas em pequenos espaços (GIRACCA, 1998).

A minhocultura é uma alternativa simples o que vem a facilitar a sua adoção pelos agricultores familiares. É uma atividade rentável, exige mínima mão-de-obra, sendo a implantação do minhocário a etapa em se que precisa de maior dispêndio de trabalho e dependendo do objetivo da criação, também é o período de maior gasto. $\mathrm{Na}$ agricultura familiar, o fator econômico pode ser contornado com a utilização de materiais oriundos da própria propriedade, fornecendo às minhocas resíduos vegetais e esterco principalmente o bovino como principal fonte de alimentação (HENTZ et al., 2008). Os movimentos sociais do campo na Amazônia também tem se apropriado dessa discussão para a construção de uma identidade agroflorestal. Nessa perspectiva o foco tem sido a relação do homem com a natureza e de como equilibrar a necessidade de desenvolver as atividades produtivas de maneira sustentável e com práticas amigáveis de uso da terra com bases agroecológicas. A utilização de vemicomposto é uma das alternativas que podem auxiliar na minimização da dependência por insumos químicos para a produção vegetal e estimular a transição agroecológica na agricultura familiar.

Segundo o processo de compostagem e a ação das minhocas alteram qualitativa e quantitativamente a composição das substâncias húmicas e dos materiais orgânicos. O material humificado apresenta como vantagens maior capacidade de troca de cátions, maior retenção de umidade e mineralização mais lenta. Os excrementos de minhocas aumentam três a onze vezes o teor de fósforo assimilável, de potássio e magnésio trocáveis no solo, e ainda eleva de cinco a dez vezes o teor de nitratos e em $30 \%$ o de cálcio, reduzindo a acidez dos solos. A composição e as propriedades físico-químicas dos dejetos aceleram em até $60 \%$ o desenvolvimento de bactérias, protozoários e outros microrganismos, inclusive das bactérias que fixam o nitrogênio. Estes mesmos microrganismos multiplicados no processo tornam mais rápida a fermentação de restos vegetais e animais, que podem ser melhor aproveitados pelas plantas (ZEOLA; SILVA SOBRINHO; GONZAGA NETO, 2006).

Além de todos estes benefícios, a vermicompostagem através da criação de minhocas Eisenia foetida, pode contribuir para a rentabilidade econômica do agricultor familiar, gerando um excedente em sua produção. O objetivo deste trabalho foi fomentar as ações de pesquisa e extensão como a implantação e acompanhamento de 
minhocário experimental no campus da UFPA e Escola Família Agrícola (EFA), na Federação das Cooperativas da Agricultura Familiar do Sul do Pará (FECAT), e em Assentamentos da região, distribuição de matrizes para a formação de minhocários na região e distribuição do vermicomposto, difundindo tecnologias de baixo custo para a reciclagem de resíduos vegetais através da criação de minhocas Eisenia foetida.

\section{MATERIAL E MÉTODOS}

O trabalho foi desenvolvido no âmbito do projeto "Introdução de programa de extensão agroflorestal no curso de Agronomia de Marabá através da criação de minhocas Eisenia foetida para a produção de vermicomposto" implementado pela Proex (Pibex 2007-2011) e curso de Agronomia da Universidade Federal do Pará - Campus Marabá desde 2007, que prima pela articulação entre ensino-pesquisa-extensão nas atividades curriculares no percurso formativo dos graduandos com enfoque na realidade regional.

As atividades curriculares desenvolvidas no curso e nos projetos de pesquisa e desenvolvimento fomentaram as ações de pesquisa e extensão deste trabalho, sendo elas: a) Implantação de minhocários experimentais; b) Acompanhamento da reprodução das minhocas e produção do vermicomposto nos minhocários experimentais; c) Seminário de planejamento para implantação de módulo agroflorestal e do minhocário na Escola Família Agrícola (EFA); d) Seminários e dias de campo para a divulgação de técnicas de vermicompostagem e construção de minhocários nos Assentamentos agrícolas da região e na Federação das Cooperativas da Agricultura Familiar do Sul do Pará (FECAT); e) Distribuição do excedente das matrizes de minhocas para a formação de novos minhocários e do vermicomposto.

\section{RESULTADOS E DISCUSSÃO}

A difusão das técnicas ocorreu primeiramente na EFA e posteriormente na Federação das Cooperativas da Agricultura Familiar do Sul do Pará (FECAT) e no projeto de assentamento Belo Horizonte I em São Domingos do Araguaia, e posteriormente no PA Palmares II em Parauapebas e PA Araras em São João do Araguaia. O minhocário experimental foi construído na EFA, na forma de mutirão, em uma caixa d'água de fibrocimento de $1 \mathrm{~m}^{2}$, com cobertura de folhas de babaçu, e o substrato para as minhocas foi o esterco bovino e restos vegetais oriundos da cozinha da escola. O excedente de minhocas foi distribuído na FECAT, e nos Assentamentos para a implantação de novos minhocários, 1 em cada Assentamento. O vermicomposto produzido foi etiquetado e guardado para ser distribuído para outros agricultores interessados na produção de frutíferas e olerícolas ou para 
experimentos realizados pelos graduandos da UFPA em casa de vegetação. Desde o início do projeto $1000 \mathrm{~kg}$ de vermicomposto foram distribuídos e 8 minhocários foram construídos.

No minhocário experimental da EFA, foi verificada uma produção média de 350 $\mathrm{kg} / \mathrm{m}^{2}$ de vermicomposto e a reprodução das minhocas variou de 600 a 5000 minhocas a cada 60 dias, corroborando com dados de Santos (2009). Sempre que quantifica o povoamento de canteiros, a unidade de medida usual é o litro, sendo que um litro de minhocas corresponde a $1 \mathrm{~kg}$ e tratando-se da espécie Eisenia foetida um litro contém em média, 1.200 a 1.500 minhocas, dependendo do tamanho das matrizes. A ação de distribuição do excedente das matrizes do minhocário experimental para a formação de novos minhocários foi considerada satisfatória, pois foram instalados um minhocário na FECAT para o aproveitamento dos resíduos de frutas da cooperativa e três outros em diferentes assentamentos.

O minhocário experimental serviu de modelo para a difusão desta tecnologia de baixo custo para a reciclagem de resíduos vegetais junto aos produtores, técnicos e estudantes, bem como para a produção e utilização do vermicomposto na produção de mudas de frutíferas e essências florestais para a implantação de SAF e produção de olerícolas.

\section{CONCLUSÕES}

A difusão e implantação de minhocários para a produção de vermicomposto, através da articulação de ensino-pesquisa-extensão, pode auxiliar na transição agroecológica das unidades de produção familiares, através da produção de mudas de qualidade seja de frutíferas, essências florestais ou no cultivo de olerícolas, contribuindo para o manejo sustentável da agricultura familiar na região.

\section{REFERÊNCIAS}

HENTZ, A. M., MOTA, J. C., SILVA, A. L., PEREIRA, S. L. Criação de minhocas Eisenia foetida em diferentes substratos para a produção de vermicomposto. In: SEMANA DE INTEGRAÇÃO DAS CIÊNCIAS AGRÁRIAS, 8., 2008, Altamira. Anais... Altamira: UFPA, 2008. p.36-40.

GIRACCA, E. M. N. Resultados projeto piloto, vermicompostagem do lixo urbano da UTAR. Santa Maria, RS: Universidade Federal de Santa Maria, 1998. 12 p. (Boletim Técnico, n. 1).

MARTINEZ, A. A. Minhocultura. 2006. Artigo em Hypertexto. Disponível em: http://www.infobibos.com/artigos/2006_2/mi nhocultura/index.htm Acesso em: 27 set. 2007.

MARTINEZ, A. A. Manual prático do minhocultor. Jaboticabal: FUNEP, 137 p. 1995. 
SANTOS, F. C. Criação de Minhocas Eisenia andrei B. em diferentes substratos para a produção de vermicomposto. 2009. $48 \mathrm{f}$. Trabalho de Conclusão de curso (Bacharelado em Agronomia) - Faculdade de Ciências Agrárias de Altamira da Universidade Federal do Pará. Altamira. 2009.

SCHIEDECK, G., GONÇALVES, M. de M., SCHWENGBER, J. E. Minhocultura e produção de húmus para a agricultura familiar. Local: São Paulo. Editora: Nova Odessa, 2006. (Desenvolvimento de material didático ou instrucional - Comunicado Técnico).

ZEOLA, N. M. B. L.; SILVA SOBRINHO, A. G.; GONZAGA NETO, S. Compostagem e vermicompostagem na ovinocultura. 2006. Disponível em: $<$ http://www.aspaco.org.br/materias.php?id=2 78>. Acesso em: 14 mai. 2010. 